Research Paper

\title{
Clinical outcomes of patients hospitalized for COVID-19 versus SARS: a meta-analysis
}

\author{
Po-Cheng Chang ${ }^{1, *}$, Chien-Chang Yang ${ }^{2, *},{ }^{*}$ Kuo-Chin $\mathrm{Kao}^{3}$, Ming-Shien Wen ${ }^{1}$ \\ ${ }^{1}$ Division of Cardiology, Department of Internal Medicine, Chang Gung Memorial Hospital, Linkou and Chang Gung \\ University, Medical School, Taoyuan, Taiwan \\ ${ }^{2}$ Division of Infectious Diseases, Department of Internal Medicine, Chang Gung Memorial Hospital, Linkou and \\ Chang Gung University, Medical School, Taoyuan, Taiwan \\ ${ }^{3}$ Division of Thoracic Medicine, Department of Internal Medicine, Chang Gung Memorial Hospital, Linkou and \\ Chang Gung University, Medical School, Taoyuan, Taiwan \\ *Equal contribution
}

Correspondence to: Ming-Shien Wen; email: wenms123@gmail.com, https://orcid.org/0000-0002-0056-7985

Keywords: COVID-19, severe acute respiratory syndrome (SARS), fatality

Received: June 18, $2020 \quad$ Accepted: September 20, $2020 \quad$ Published: November 24, 2020

Copyright: (c) 2020 Chang et al. This is an open access article distributed under the terms of the Creative Commons Attribution License (CC BY 3.0), which permits unrestricted use, distribution, and reproduction in any medium, provided the original author and source are credited.

\begin{abstract}
Estimating the case-fatality rate and clinical outcomes for patients with coronavirus disease 2019 (COVID-19) is crucial because health care systems must adequately prepare for outbreaks and design appropriate policies. A systematic search of PubMed, Embase, and Medline+Journal (via OVID) were conducted for relevant journal publications from database inception to May 4, 2020. Articles that reported the fatality rates and clinical outcomes of patients hospitalized for COVID-19 or severe acute respiratory syndrome (SARS) infection were included. Nine clinical reports (four SARS reports and five COVID-19 reports) with a total of 851 patients (367 and 484 patients with SARS and COVID-19, respectively) were analyzed. A greater proportion of hospitalized patients with COVID-19 had bilateral pneumonia $(90.0 \%$ [76.3\%-96.2\%] vs. $35.9 \%$ [21.4\%-53.6\%], $p<0.001)$ and required ventilators $(23.8 \%$ [18.8\%-29.6\%] vs. 15.3\% [11.9\%-19.4\%], $p=0.010)$ compared with hospitalized patients with SARS. The case-fatality rate was $9.5 \%(6.5 \%-13.7 \%)$ and $6.1 \%(3.5 \%-10.3 \%)$ among patients with COVID-19 and SARS, respectively $(p=0.186)$. The case-fatality rate among hospitalized patients with COVID-19 was comparable to that during the 2003 SARS outbreak. A higher incidence of bilateral pneumonia and increased ventilator usage were noted among patients with COVID-19 compared with patients with SARS.
\end{abstract}

\section{INTRODUCTION}

The ongoing coronavirus disease 2019 (COVID-19) pandemic is caused by SARS-CoV-2. The 2003 outbreak of severe acute respiratory syndrome (SARS) and the 2012 outbreak of Middle East respiratory syndrome were also caused by coronaviruses. The COVID-19 [1] and SARS outbreaks [2] were both first reported in China, and they had similar clinical presentations. How the case-fatality rates of COVID19 and SARS infections compare is a matter of ongoing debate. The total case-fatality rate among patients with SARS in 2003 was $9.6 \%$, and the case-fatality rate was $15.3 \%$ among patients in countries other than China [3]. Early reports revealed a $5 \%-16 \%$ case-fatality rate among patients hospitalized for COVID-19 pneumonia [4-8]. However, a report from the Chinese Center for Disease Control and Prevention estimated an overall case-fatality rate of $2.3 \%$ [9]. Some reports have implied that COVID-19 infection has a lower case-fatality rate than SARS infection $[10,11]$. 
Estimating case-fatality rates is crucial because health care systems must adequately prepare for outbreaks and implement appropriate policies. However, determining the case-fatality rate during the COVID-19 pandemic is challenging. In particular, real-time report databases and clinical observation without adequate follow-up during the outbreak may provide misleading information. During an overwhelming outbreak, shortages of diagnostic tests and therapeutic resources can result in distorted outcome data. Accurate records of symptoms and presentations are essential for estimating outcomes. Therefore, we considered that medical data acquired from hospitalized patients may satisfy the fundamental requirements for accuracy.
The objective of this study was to compare clinical outcomes in patients hospitalized for COVID-19 with those of patients hospitalized for SARS. This study assessed case-fatality rate, pulmonary infiltration in chest radiography, pneumonia over the bilateral lungs, progression to acute respiratory distress syndrome (ARDS), ventilator use, and intensive care unit (ICU) admission rate.

\section{RESULTS}

A literature search yielded a total of 1372 records, from which we removed 669 duplicates (Figure 1). After abstract screening, we excluded 660 studies that did not

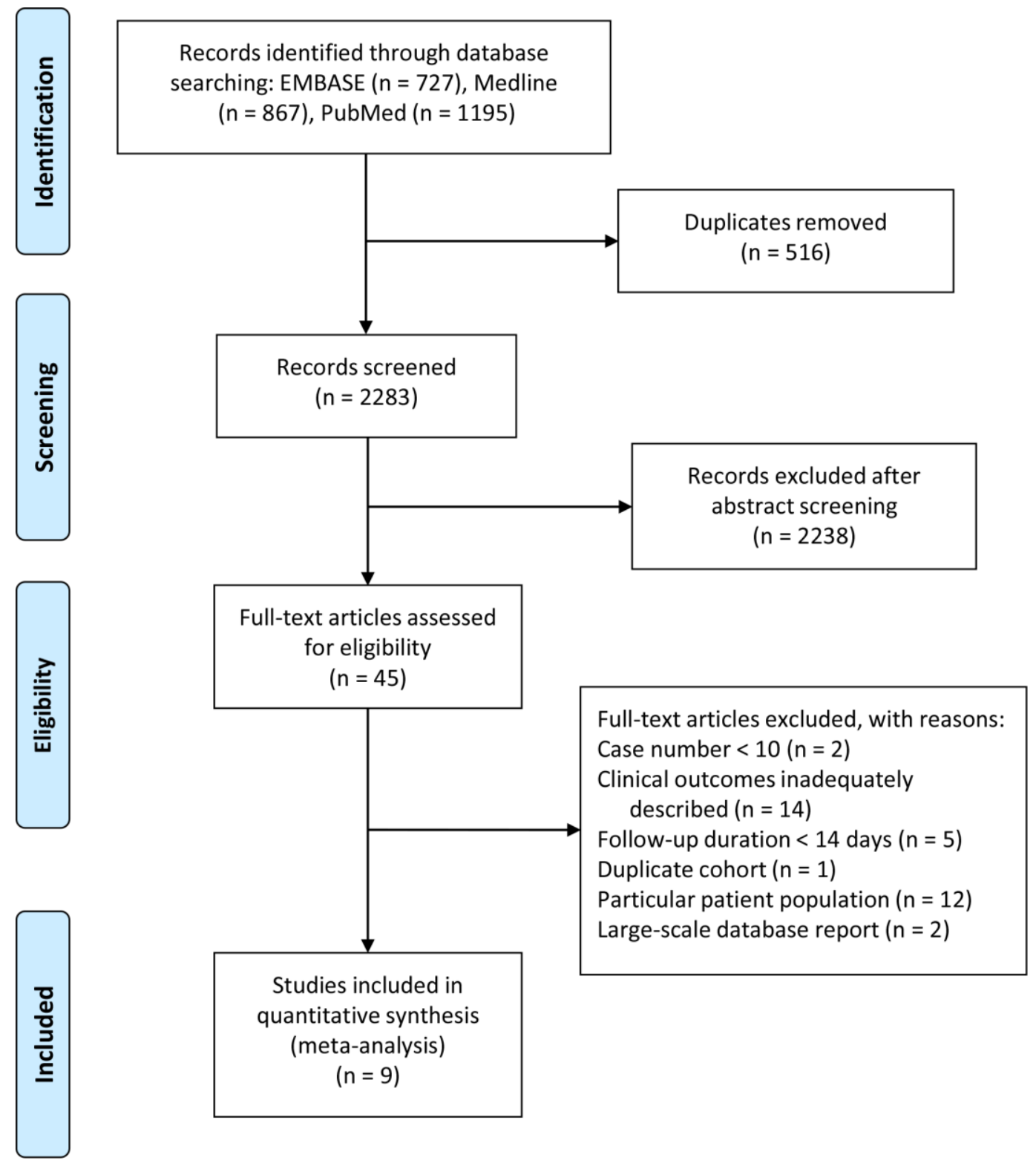

Figure 1. Study flow (PRISMA) diagram. 
Table 1. Studies of patients hospitalized with SARS and COVID-19.

\begin{tabular}{lcccccc}
\hline & Location & Diseases & N & $\begin{array}{c}\text { Bilateral or multiple } \\
\text { pneumonia }\end{array}$ & $\begin{array}{c}\text { Ventilator } \\
\text { use }\end{array}$ & Death \\
\hline Booth CM. et al, 2003 [25] & Canada & SARS & 144 & $75(52 \%)$ & $20(14 \%)$ & $8(6 \%)$ \\
Tsang KW. et al, 2003 [28] & Hong Kong & SARS & 10 & & & $2(20 \%)$ \\
Lee N. et al, 2003 [26] & Hong Kong & SARS & 138 & $49(36 \%)$ & $19(14 \%)$ & $5(4 \%)$ \\
Peiris JS. et al, 2003 [27] & Hong Kong & SARS & 75 & $16(21 \%)$ & $15(20 \%)$ & $5(7 \%)$ \\
Huang C. et al, 2020 [5] & China & COVID-19 & 41 & $40(98 \%)$ & $14(34 \%)$ & $6(15 \%)$ \\
Liu K. et al, 2020 [8] & China & COVID-19 & 137 & $116(85 \%)$ & $34(25 \%)$ & $16(12 \%)$ \\
Chen N. et al, 2020 [4] & China & COVID-19 & 99 & $74(75 \%)$ & $17(17 \%)$ & $11(11 \%)$ \\
Wang D. et al, 2020 [6] & China & COVID-19 & 138 & $138(100 \%)$ & $32(23 \%)$ & $6(4 \%)$ \\
Wang Z. et al, 2020 [7] & China & COVID-19 & 69 & & & $5(7 \%)$ \\
\hline
\end{tabular}

fulfill the inclusion criteria. After assessing the full text of 45 articles, we included 4 SARS articles (for a total of 367 patients, published between March 2003 and May 2003) and 5 COVID-19 articles (484 patients, published between January 2020 and March 2020). Table 1 shows the included studies and the main outcomes. In these papers, the diagnostic criteria for SARS were defined by the United States Centers for Disease Control and Prevention and the World Health Organization (WHO) [3]. As the time of the SARS outbreak, reverse-transcriptase polymerase chain reaction (RT-PCR) was not yet being widely applied for obtaining diagnostic confirmation, and only 20 patients with SARS received the RT-PCR test retrospectively. In the COVID-19 papers, the diagnostic criteria for COVID-19 infection included a positive SARS-CoV-2 RT-PCR test as specified by WHO interim guidance [12].

\section{Patient characteristics and clinical presentation}

Demographics, comorbidities, and clinical presentations are listed in Table 2. Among the included articles, the 484 patients with COVID-19 were older than the 367 patients with SARS $(53.0 \pm 4.9$ years and $42.0 \pm 3.2$ years, respectively, $\mathrm{p}<0.001)$. There were more male patients in the COVID-19 group than in the SARS group (54.8\% and $44.1 \%, \mathrm{p}<0.001)$. The COVID-19 group had a higher prevalence of chronic diseases than the SARS group did, such as cardiovascular diseases $(17.4 \%$ and $5.8 \%, \mathrm{p}<$ $0.001)$, hypertension $(17.2 \%$ and $10.0 \%, \mathrm{p}=0.018)$, diabetes $(10.2 \%$ and $7.9 \%, \mathrm{p}<0.001)$, and chronic obstructive pulmonary disease (COPD) $(2.9 \%$ and $1.7 \%$, $\mathrm{p}<0.001$ ). More patients with COVID-19 presented with cough, sputum production, and malaise than patients with SARS; however, fever, myalgia, headache, dizziness, sore throat, nausea or vomiting, and diarrhea were more common in patients with SARS than in patients with COVID-19. Patients with COVID-19 had a higher level of B-type natriuretic peptide (BNP) than patients with SARS. However, patients with SARS had a higher level of creatinine and alanine transaminase (ALT) than did patients with COVID-19.

\section{Outcome analyses}

Figure 2 presents a comparison of clinical outcomes between study groups. Hospitalized patients with COVID-19 and SARS frequently developed pneumonia. Among the hospitalized patients, a higher percentage of those with COVID-19 had an initial presentation of lung infiltration (99.4\% [98.1\%-99.8\%]) than those with SARS $(81.5 \%$ [70.1\%-89.2\%], $\mathrm{p}<0.001)$. Patients with COVID-19 had a higher likelihood (90.0\% [76.3\%96.2\%]) of developing bilateral pneumonia than patients with SARS $(35.9 \%$ [21.4\%-53.6\%], $\mathrm{p}<0.001)$.

Although the data concerning ICU admission were limited, the rate of ICU admission was higher among patients with COVID-19 (27.4\% [21.4-34.4\%]) than among those with SARS (20.8\% [16.9\%-25.4\%]; $\mathrm{p}=$ $0.088)$. A notably higher proportion of patients with COVID-19 required a mechanical ventilator $(23.8 \%$ [18.8\%-29.6\%]) than that of patients with SARS (15.3\% [11.9\%-19.4\%]; $\mathrm{p}=0.010)$. However, the proportions of patients who progressed to ARDS were comparable between patients with COVID-19 (20.6\% [15.5\%-26.8\%] and patients with SARS (20.0\% [12.4\%-30.6\%]; $\mathrm{p}=0.913)$. As indicated in Figure 2, high case-fatality rates were observed both for hospitalized patients with COVID-19 (9.5\% [6.5\%13.7\%]) and hospitalized patients with SARS (6.1\% [3.5\%-10.3\%]; $\mathrm{p}=0.186$ ).

Supplementary Figures 1-12 show funnel plots for the assessment of publication bias. Egger's tests indicated no significance, with the exception of the results for lung infiltration from the COVID-19 studies ( $p=$ 0.002). Analyses of publication bias could not be performed for ICU admission rates from the COVID-19 studies nor for ARDS from the SARS studies because fewer than three studies were available. 
Table 2. Demographics, comorbidities, and clinical presentations of patients with COVID-19 and SARS.

\begin{tabular}{|c|c|c|c|c|c|}
\hline \multirow{2}{*}{ Variable } & \multicolumn{2}{|c|}{ COVID-19 } & \multicolumn{2}{|c|}{ SARS } & \multirow{2}{*}{$P$ value } \\
\hline & Valid $n$ & Data & Valid $n$ & Data & \\
\hline \multicolumn{6}{|l|}{ Demographics } \\
\hline Age, year & 484 & $53.0 \pm 4.9$ & 367 & $42.0 \pm 3.2$ & $<0.001$ \\
\hline Male & 484 & $265(54.8)$ & 367 & $162(44.1)$ & $<0.001$ \\
\hline \multicolumn{6}{|l|}{ Comorbidity } \\
\hline Cardiovascular disease & 484 & $84(17.4)$ & 292 & $17(5.8)$ & $<0.001$ \\
\hline Hypertension & 443 & $76(17.2)$ & 10 & $1(10.0)$ & 0.018 \\
\hline Chronic liver disease & 248 & $6(2.4)$ & 213 & $10(4.7)$ & $<0.001$ \\
\hline Diabetes & 344 & $35(10.2)$ & 292 & $23(7.9)$ & $<0.001$ \\
\hline Chronic obstructive pulmonary disease & 385 & $11(2.9)$ & 292 & $5(1.7)$ & $<0.001$ \\
\hline \multicolumn{6}{|l|}{ Clinical presentation } \\
\hline Fever & 484 & $430(88.8)$ & 367 & $366(99.7)$ & $<0.001$ \\
\hline Myalgia & 484 & $142(29.3)$ & 367 & $211(57.5)$ & $<0.001$ \\
\hline Cough & 415 & $260(62.7)$ & 367 & $209(56.9)$ & $<0.001$ \\
\hline Sputum & 344 & $63(18.3)$ & 292 & $48(16.4)$ & 0.043 \\
\hline Malaise & 275 & $140(50.9)$ & 144 & $45(31.3)$ & $<0.001$ \\
\hline Dizziness & 207 & $18(8.7)$ & 357 & $68(19.0)$ & $<0.001$ \\
\hline Headache & 484 & $43(8.9)$ & 367 & $146(39.8)$ & $<0.001$ \\
\hline Sore throat & 306 & $35(11.4)$ & 367 & $61(16.6)$ & $<0.001$ \\
\hline Nausea or vomiting & 306 & $9(2.9)$ & 292 & $56(19.2)$ & $<0.001$ \\
\hline Diarrhea & 484 & $38(7.9)$ & 357 & $62(17.4)$ & $<0.001$ \\
\hline \multicolumn{6}{|l|}{ Lab data } \\
\hline Hemoglobin, g/dL & 209 & $12.9 \pm 0.2$ & 223 & $13.4 \pm 0.1$ & $<0.001$ \\
\hline Platelet count, $\times 1,000 / \mu \mathrm{L}$ & 168 & $196.0 \pm 21.0$ & 367 & $168.0 \pm 16.2$ & $<0.001$ \\
\hline White blood count, $/ \mu \mathrm{L}$ & 347 & $5422 \pm 1469$ & 367 & $5439 \pm 541$ & 0.832 \\
\hline Neutrophil, $/ \mu \mathrm{L}$ & 347 & $3678 \pm 1115$ & 282 & $3747 \pm 150$ & 0.302 \\
\hline Lymphocyte, $/ \mu \mathrm{L}$ & 347 & $898 \pm 133$ & 292 & 900 & 0.810 \\
\hline Creatinine, $\mathrm{mg} / \mathrm{dL}$ & 347 & $0.89 \pm 0.23$ & 367 & $0.99 \pm 0.11$ & $<0.001$ \\
\hline $\mathrm{BUN}, \mathrm{md} / \mathrm{dL}$ & 237 & $14.1 \pm 2.1$ & 282 & $12.7 \pm 1.6$ & $<0.001$ \\
\hline Bilirubin total, $\mathrm{mg} / \mathrm{dL}$ & 140 & $0.82 \pm 0.09$ & 357 & $0.86 \pm 0.72$ & 0.540 \\
\hline $\mathrm{ALT}, \mathrm{U} / \mathrm{L}$ & 347 & $29.4 \pm 6.5$ & 367 & $47.5 \pm 14.9$ & $<0.001$ \\
\hline BNP, pg/mL & 237 & $14.1 \pm 2.1$ & 282 & $12.7 \pm 1.6$ & $<0.001$ \\
\hline
\end{tabular}

Data are presented as a number (percentage) or the mean \pm standard deviation.

ALT, alanine transaminase; BUN, blood urea nitrogen; BNP, B-type natriuretic peptide.

\section{DISCUSSIONS}

In the included articles, patients hospitalized for COVID-19 had a higher average age than those hospitalized for SARS. The prevalence of cardiovascular disease, hypertension, diabetes, and COPD among patients with COVID-19 was also higher than that among patients with SARS. Although reports showed a high prevalence of asymptomatic carriers or cases with minimal symptoms among patients with COVID-19, COVID-19 infection was associated with a higher rate of abnormal chest radiography findings than was SARS infection. Hospitalized patients with COVID-19 also had a greater risk of developing bilateral pneumonia and a higher prevalence of progression to ARDS compared with patients hospitalized for SARS infection. The case-fatality rates among patients hospitalized for COVID-19 and SARS infection were similarly high.

\section{Clinical presentations}

Clinical presentations did not include the loss of smell or loss of taste as symptoms in the eligible articles. Researchers have recently become aware of olfactory and gustatory disorders as prevalent symptoms among patients with COVID-19, who may not have other airway symptoms [13]. Whether patients with SARS also developed loss of smell or loss of taste is unclear. Notably, anosmia was found in one case reported during the SARS outbreak [14].

Clinical manifestations are not the only indicators of active virus shedding. Although most patients included 
in this study were symptomatic, asymptomatic COVID19 and SARS infections and colonizations were also present [15-17]. Asymptomatic patients were able to spread the virus to other members of the public. Moreover, some patients could spread the virus even after recovering from COVID-19 or SARS infection $[18,19]$. Asymptomatic carriers or patients with few symptoms may pose problems for containing virus outbreaks. Therefore, wearing a facemask could be helpful for containment in light of silent spreaders.

\section{High prevalence of cardiovascular disease, hypertension, and diabetes}

The COVID-19 group had a higher prevalence of cardiovascular disease, hypertension, and diabetes than the SARS group. SARS-CoV-2, like other coronaviruses, utilizes spike glycoprotein to bind to angiotensin-converting enzyme 2 (ACE2) on the host cell surface [20]. One report showed that the affinity of SARS-CoV-2 to human ACE2 is higher than that of SARS-CoV [21]. The use of ACE inhibitors and angiotensin-converting enzyme blockers (ARBs) increases cellular expression of ACE2 [22]. This finding may partially explain the higher prevalence of cardiovascular disease, hypertension, and diabetes in the COVID-19 group than in the SARS group. Increased ACE2 expression raises the concern of using ACE inhibitors or ARBs in patients with COVID-19 infection. However, adequate evidence to confirm the causal association between the use of ACE inhibitors or ARBs and a higher risk of COVID-19 infection is lacking. A recent report indicated that the use of ACE inhibitors and $\mathrm{ARBs}$ was more common among patients with COVID-19 than among controls because of their higher prevalence of cardiovascular disease rather than because of their use of these medications [23].

\section{Variation of outcome estimation}

Estimation of case outcomes may vary by country because of differences in mitigation policies, diagnostic criteria, extent of RT-PCR tests, and availability of health care. Patients commonly remain asymptomatic or have mild symptoms after COVID-19 or SARS infection. Many patients without severe symptoms were not counted as confirmed cases. In one RT-PCR study, approximately $11.5 \%$ of well-protected health care

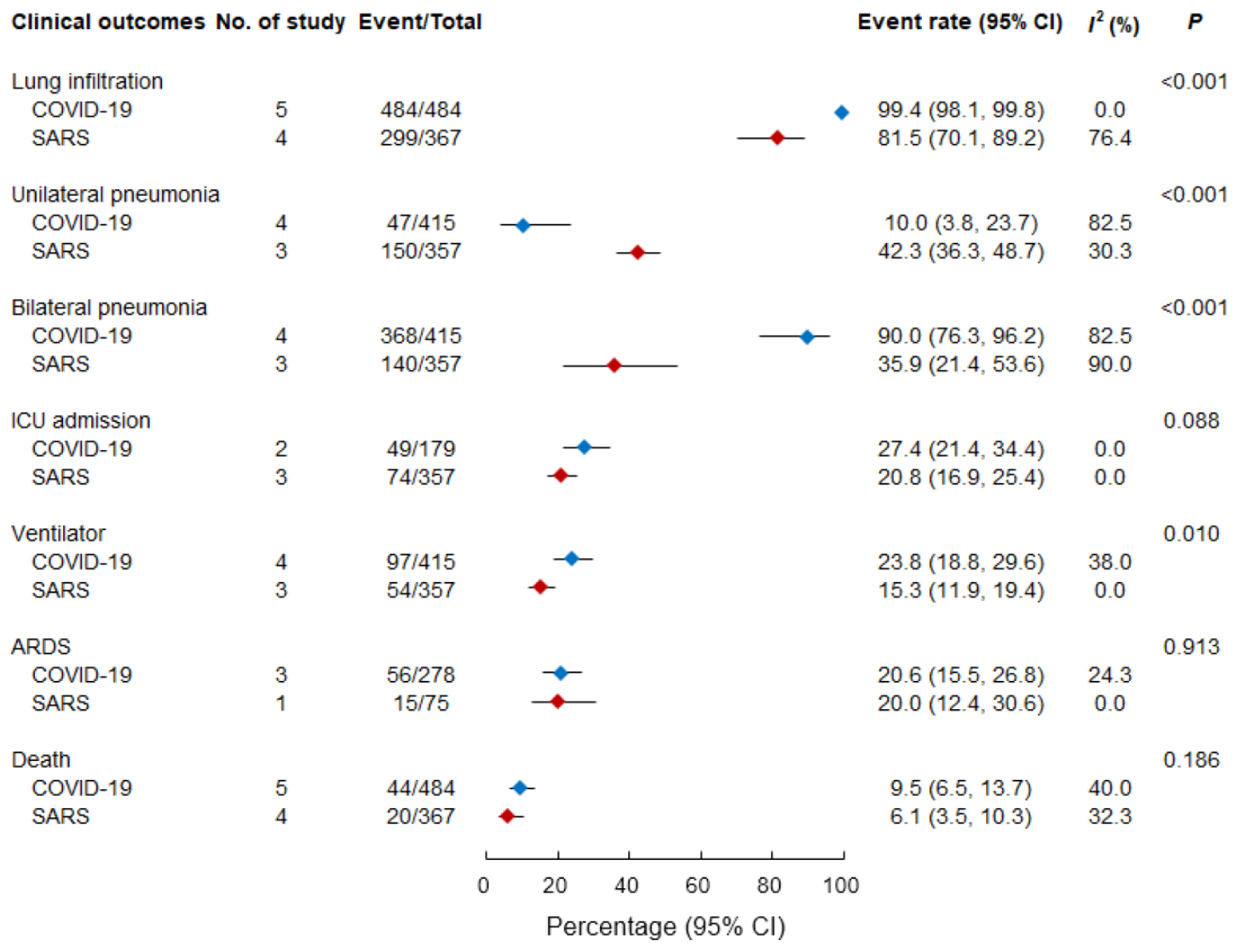

Figure 2. Pooled event rate of clinical outcomes in patients with COVID-19 and SARS. ARDS, acute respiratory distress syndrome; ICU, intensive care unit; SARS, severe acute respiratory syndrome. 
workers exposed to patients with SARS were found to have virus colonization or infection, and only approximately $10 \%$ of these developed severe symptoms [16]. Another report also revealed that $78 \%$ of cases identified during the COVID-19 outbreak were asymptomatic [15]. The policies for RT-PCR swab tests vary among countries: some conduct extensive testing, and some provide testing only for symptomatic cases. These findings demonstrate that accurate estimation is a challenge. However, many fatal cases may go unrecognized because they did not fulfill the testing criteria or because health care institutions are unable to provide testing during overwhelming outbreaks. These variations mean that estimates of case fatality in largescale patient populations are unreliable. Therefore, we assessed patient outcomes of a hospitalized population from reports by using data observed directly in hospitals.

From a public health perspective, accurate clinical outcome estimates are essential for officials to make adequate preparations and implement appropriate policies for virus containment. As of April 12, 2020, Taiwan had a total of 388 confirmed COVID-19 cases, including only 54 locally transmitted cases. The case number was far fewer than anticipated, with initial models predicting that Taiwan would be at the secondhighest risk of imported cases [24]. Initial reports of the COVID-19 outbreak in Wuhan, China [4-8] revealed a similar clinical pattern to that of the SARS outbreak in 2003 [25-28]. Early precautions and awareness of the disease's severity played a prominent role in Taiwan's success in containing COVID-19 [29].

\section{Limitations}

The diagnostic criteria for SARS and COVID-19 were different. The COVID-19 reports included patients who fulfilled the WHO diagnostic criteria and had positive RT-PCR test results. However, the diagnostic criteria for SARS were based on clinical presentation and history of direct contact with a person who became ill after exposure to an index patient.

The patient populations were also different: the COVID-19 group was older, had more male patients, and had a higher prevalence of chronic diseases than the SARS group did. The poorer outcomes among patients with COVID-19 may be associated with their older age and higher prevalence of chronic diseases.

These two outbreaks occurred in different countries and regions. The case-fatality rate is substantially affected by the preparedness and availability of health care services. Health care systems have advanced in the past two decades, and most institutions were able to manage ARDS. The fatality rate may increase during fast-spreading periods, and the reports analyzed in this study were published before overwhelming COVID-19 or SARS outbreaks.

Patients with mild symptoms were not included in this study; therefore, the study lacks a direct comparison of severity scores between patients who were hospitalized for COVID-19 and those hospitalized for SARS. We do not reject the possibility of different severities between these two groups because the existing data are insufficient to measure the severity of pneumonia. The reports included only hospitalized patients, and thus patients with mild symptoms were not included. During the 2003 SARS outbreak, some of these cases of mild infection were also undetected because of limited molecular diagnostic tools. In an RT-PCR study, approximately $11.5 \%$ of well-protected health care workers exposed to patients with SARS were found to have virus colonization or infection, and only approximately $10 \%$ of these developed severe symptoms [16]. According to epidemiological reports [30], positive anti-SARS-CoV immunoglobin G seroprevalence was $0.23 \%$ among SARS health care workers and $0.10 \%$ among healthy individuals, indicating the existence of undiagnosed patients with SARS with relatively mild symptoms. During the early stages of the SARS and COVID-19 outbreaks, physicians admitted patients on the basis of clinical judgment rather than positive molecular test results. Therefore, the severity of pneumonia in the case studies should indicate the fulfillment of criteria for admission.

\section{CONCLUSIONS}

In summary, the patients hospitalized for COVID-19 were older and had a higher prevalence of chronic diseases than patients hospitalized for SARS. COVID-19 infection was associated with a higher rate of abnormal chest radiography findings, a greater risk of developing bilateral pneumonia, and a higher incidence of progression to ARDS compared with SARS infection. The case-fatality rate was similarly high among patients hospitalized for COVID-19 and SARS infections.

\section{MATERIALS AND METHODS}

\section{Search strategy and selection criteria}

This meta-analysis of published studies was conducted following the Preferred Reporting Items for Systematic Reviews and Meta-Analyses (PRISMA) guidelines. A systematic search of PubMed, Embase (via Ovid), and Medline journals (via Ovid) was conducted. The database search period was from database inception to May 4, 2020. The complete search algorithms are provided in the supplementary data. The keywords included a 
combination of severe acute respiratory syndrome, SARS, SARS-CoV-2, COVID-19, coronavirus, and case report (see Supplementary Material 1). Only full-text English-language journal articles and research involving humans were included. Two researchers (Chang PC and Yang CC) evaluated the included studies by using the United States National Heart, Lung, and Blood Institute and Research Triangle Institute Study Quality Assessment (Supplementary Table 1). All included studies were assessed for quality. The two researchers independently extracted clinical presentation and outcome data. The data were reevaluated, and consensus was reached in the case of discrepancies.

\section{Eligibility criteria}

All clinical reports that included clinical outcomes (including chest radiography presentations, ventilator support, ICU admission, and death) for COVID-19 and SARS infection were included. Case reports or case series with fewer than 10 patients were excluded. Papers reporting only laboratory outcomes, radiology presentations, or epidemiological information rather than detailed clinical outcomes were also excluded. Because clinical outcomes are time dependent, papers were also excluded if the follow-up duration of the enrolled patients was less than 14 days. We did not include studies that enrolled only particular patient populations, such as pregnant women, fatal cases, patients undergoing hemodialysis, or asymptomatic cases. If papers were based on the same group of patients, we included the article with the largest patient group and the most complete outcome data. Because the disease severity in hospital-based direct observation studies was discrepant with data from large-scale database reports, this study included only hospital-based direct observation studies (Figure 1).

\section{Data extraction}

Relevant information was collected by Chang PC and Yang CC. The study-level characteristics extracted were the name of first author, publication year, region, number of patients, patient demographics (age and sex), 6 types of comorbidity, 10 categories of clinical presentation, and 10 types of laboratory results (if available). Data for outcomes of interest were collected, including abnormal chest radiography results, unilateral pneumonia, bilateral pneumonia, ICU admission, progression to ARDS, ventilator usage, and death.

\section{Data analysis}

This meta-analysis included studies that did not directly compare the study groups (COVID-19 and SARS) and pooled rates of events from the included studies for comparison. Random-effects models were used to pool the estimates (the rates of events) of clinical outcomes from individual studies for each study group. An $I^{2}$ value greater than $50 \%$ was considered to indicate substantial heterogeneity across the studies. The pooled estimates between COVID-19 and SARS were compared using mixed-effects models. Statistical significance was set at a two-tailed $\mathrm{p}$ value of $<0.05$. Publication bias was assessed using a visual check of the funnel plot together with Egger's test. Data were analyzed using Comprehensive Meta-Analysis software (version 3; Biostat, Englewood, NJ, USA).

\section{Abbreviations}

ACE: Angiotensin-converting enzyme; ALT: Alanine transaminase; ARB: Angiotensin-converting enzyme blocker; ARDS: Acute respiratory distress syndrome; BNP: B-type natriuretic peptide; COPD: Chronic obstructive pulmonary disease; ICU: Intensive care unit; PRISMA: Preferred reporting items for systematic reviews and meta-analyses; RT-PCR: Reverse transcription polymerase chain reaction; SARS: Severe acute respiratory syndrome; WHO: World Health Organization.

\section{AUTHOR CONTRIBUTIONS}

Chang PC and Wen MS conceived of the presented study. Chang PC and Yang CC collected data and conducted analyses. Kao KC and Wen MS verified the analytical methods. Chang PC and Yang $\mathrm{CC}$ drafted the manuscript. All authors discussed the results and contributed to drafting the final manuscript.

\section{ACKNOWLEDGMENTS}

We thank Mr. Alfred Hsing-Fen Lin for his assistance with statistical analysis during the completion of this manuscript. This manuscript was edited by Wallace Academic Editing.

\section{CONFLICTS OF INTEREST}

These authors declare no conflicts of interest.

\section{FUNDING}

This study was supported by the Chang Gung Research Database and the Chang Gung Medical Foundation (BMRP D62 to Chang PC).

\section{REFERENCES}

1. Zhu N, Zhang D, Wang W, Li X, Yang B, Song J, Zhao X, Huang B, Shi W, Lu R, Niu P, Zhan F, Ma X, et al, and 
China Novel Coronavirus Investigating and Research Team. A novel coronavirus from patients with pneumonia in China, 2019. N Engl J Med. 2020; 382:727-33.

https://doi.org/10.1056/NEJMoa2001017

PMID:31978945

2. Christian MD, Poutanen SM, Loutfy MR, Muller MP, Low DE. Severe acute respiratory syndrome. Clin Infect Dis. 2004; 38:1420-27.

https://doi.org/10.1086/420743 PMID:15156481

3. WHO. Consensus document on the epidemiology of severe acute respiratory syndrome (SARS). 2003. https://apps.who.int/iris/handle/10665/70863

4. Chen N, Zhou M, Dong X, Qu J, Gong F, Han Y, Qiu Y, Wang J, Liu Y, Wei Y, Xia J, Yu T, Zhang X, Zhang L. Epidemiological and clinical characteristics of 99 cases of 2019 novel coronavirus pneumonia in Wuhan, China: a descriptive study. Lancet. 2020; 395:507-13. https://doi.org/10.1016/S0140-6736(20)30211-7 PMID:32007143

5. Huang C, Wang Y, Li X, Ren L, Zhao J, Hu Y, Zhang L, Fan G, Xu J, Gu X, Cheng Z, Yu T, Xia J, et al. Clinical features of patients infected with 2019 novel coronavirus in Wuhan, China. Lancet. 2020; 395:497-506. https://doi.org/10.1016/S0140-6736(20)30183-5 PMID:31986264

6. Wang D, Hu B, Hu C, Zhu F, Liu X, Zhang J, Wang B, Xiang $\mathrm{H}$, Cheng Z, Xiong $\mathrm{Y}$, Zhao $\mathrm{Y}$, Li Y, Wang X, Peng Z. Clinical characteristics of 138 hospitalized patients with 2019 novel coronavirus-infected pneumonia in Wuhan, China. JAMA. 2020; 323:1061-69.

https://doi.org/10.1001/jama.2020.1585 PMID: $\underline{32031570}$

7. Wang Z, Yang B, Li Q, Wen L, Zhang R. Clinical features of 69 cases with coronavirus disease 2019 in Wuhan, China. Clin Infect Dis. 2020; 71:769-77. https://doi.org/10.1093/cid/ciaa272 PMID:32176772

8. Liu K, Fang YY, Deng Y, Liu W, Wang MF, Ma JP, Xiao W, Wang $\mathrm{YN}$, Zhong $\mathrm{MH}$, Li CH, Li GC, Liu HG. Clinical characteristics of novel coronavirus cases in tertiary hospitals in Hubei Province. Chin Med J (Engl). 2020; 133:1025-31.

https://doi.org/10.1097/CM9.0000000000000744 PMID:32044814

9. Epidemiology Working Group for NCIP Epidemic Response, Chinese Center for Disease Control and Prevention. [The epidemiological characteristics of an outbreak of 2019 novel coronavirus diseases (COVID19) in China]. Zhonghua Liu Xing Bing Xue Za Zhi. 2020; 41:145-51. https://doi.org/10.3760/cma.j.issn.02546450.2020.02.003 PMID:32064853
10. Wilson N, Kvalsvig A, Barnard LT, Baker MG. Casefatality risk estimates for COVID-19 calculated by using a lag time for fatality. Emerg Infect Dis. 2020; 26:1339-441.

https://doi.org/10.3201/eid2606.200320 PMID:32168463

11. Cleri DJ, Ricketti AJ, Vernaleo JR. Severe acute respiratory syndrome (SARS). Infect Dis Clin North Am. 2010; 24:175-202. https://doi.org/10.1016/j.idc.2009.10.005 PMID:20171552

12. WHO. Clinical management of severe acute respiratory infection when Novel coronavirus (nCoV) infection is suspected: interim guidance. 2020. https://apps.who. int/iris/handle/10665/332299.

13. Lechien JR, Chiesa-Estomba CM, De Siati DR, Horoi M, Le Bon SD, Rodriguez A, Dequanter D, Blecic S, El Afia F, Distinguin L, Chekkoury-Idrissi Y, Hans S, Delgado IL, et al. Olfactory and gustatory dysfunctions as a clinical presentation of mild-to-moderate forms of the coronavirus disease (COVID-19): a multicenter European study. Eur Arch Otorhinolaryngol. 2020; 277:2251-61.

https://doi.org/10.1007/s00405-020-05965-1 PMID: $\underline{32253535}$

14. Hwang CS. Olfactory neuropathy in severe acute respiratory syndrome: report of a case. Acta Neurol Taiwan. 2006; 15:26-28. PMID:16599281

15. Day M. Covid-19: four fifths of cases are asymptomatic, China figures indicate. BMJ. 2020; 369:m1375. https://doi.org/10.1136/bmj.m1375 PMID:32241884

16. Ho HT, Chang MS, Wei TY, Hsieh WS, Hung CC, Yang HM, Lu YT. Colonization of severe acute respiratory syndrome-associated coronavirus among health-care workers screened by nasopharyngeal swab. Chest. 2006; 129:95-101.

https://doi.org/10.1378/chest.129.1.95

PMID:16424418

17. Le TQ, Takemura T, Moi ML, Nabeshima T, Nguyen LK, Hoang VM, Ung TH, Le TT, Nguyen VS, Pham HQ, Duong TN, Nguyen HT, Ngu DN, et al. Severe acute respiratory syndrome coronavirus 2 shedding by travelers, Vietnam, 2020. Emerg Infect Dis. 2020; 26:1624-26.

https://doi.org/10.3201/eid2607.200591 PMID: $\underline{32240079}$

18. Chu CM, Leung WS, Cheng VC, Chan KH, Lin AW, Chan VL, Lam JY, Chan KS, Yuen KY. Duration of RT-PCR positivity in severe acute respiratory syndrome. Eur Respir J. 2005; 25:12-14.

https://doi.org/10.1183/09031936.04.00057804 PMID:15640317 
19. Yuan J, Kou S, Liang Y, Zeng J, Pan Y, Liu L. Polymerase Chain Reaction Assays Reverted to Positive in 25 Discharged Patients With COVID-19. Clin Infect Dis. 2020; 71:2230-32.

https://doi.org/10.1093/cid/ciaa398 PMID:32266381

20. Wan Y, Shang J, Graham R, Baric RS, Li F. Receptor recognition by the novel coronavirus from Wuhan: an analysis based on decade-long structural studies of SARS coronavirus. J Virol. 2020; 94:e00127-20. https://doi.org/10.1128/JVI.00127-20 PMID:31996437

21. Walls AC, Park YJ, Tortorici MA, Wall A, McGuire AT, Veesler D. Structure, function, and antigenicity of the SARS-CoV-2 spike glycoprotein. Cell. 2020; 181:28192.e6.

https://doi.org/10.1016/i.cell.2020.02.058 PMID:32155444

22. Ferrario CM, Jessup J, Chappell $M C$, Averill DB, Brosnihan KB, Tallant EA, Diz DI, Gallagher PE. Effect of angiotensin-converting enzyme inhibition and angiotensin II receptor blockers on cardiac angiotensinconverting enzyme 2. Circulation. 2005; 111:2605-10. https://doi.org/10.1161/CIRCULATIONAHA.104.510461 PMID:15897343

23. Messerli FH, Siontis GC, Rexhaj E. COVID-19 and renin angiotensin blockers: current evidence and recommendations. Circulation. 2020; 141:2042-44. https://doi.org/10.1161/CIRCULATIONAHA.120.047022 PMID:32282224

24. Read JM, Bridgen JRE, Cummings DAT, Ho A, Jewell CP. Novel coronavirus 2019-nCoV: early estimation of epidemiological parameters and epidemic predictions. medRxiv. 2020. [Epub ahead of print]. https://doi.org/10.1101/2020.01.23.20018549

25. Booth CM, Matukas LM, Tomlinson GA, Rachlis AR, Rose DB, Dwosh HA, Walmsley SL, Mazzulli T, Avendano M, Derkach P, Ephtimios IE, Kitai I, Mederski $B D$, et al. Clinical features and short-term outcomes of 144 patients with SARS in the greater Toronto area. JAMA. 2003; 289:2801-09.
https://doi.org/10.1001/jama.289.21.JOC30885

PMID: 12734147

26. Lee $N$, Hui $D, W u A$, Chan $P$, Cameron $P$, Joynt $G M$, Ahuja A, Yung MY, Leung CB, To KF, Lui SF, Szeto CC, Chung S, Sung JJ. A major outbreak of severe acute respiratory syndrome in Hong Kong. N Engl J Med. 2003; 348:1986-94.

https://doi.org/10.1056/NEJMoa030685

PMID:12682352

27. Peiris JS, Chu CM, Cheng VC, Chan KS, Hung IF, Poon LL, Law KI, Tang BS, Hon TY, Chan CS, Chan KH, Ng JS, Zheng BJ, et al, and HKU/UCH SARS Study Group. Clinical progression and viral load in a community outbreak of coronavirus-associated SARS pneumonia: a prospective study. Lancet. 2003; 361:1767-72. https://doi.org/10.1016/s0140-6736(03)13412-5 PMID:12781535

28. Tsang KW, Ho PL, Ooi GC, Yee WK, Wang T, ChanYeung M, Lam WK, Seto WH, Yam LY, Cheung TM, Wong PC, Lam B, Ip MS, et al. A cluster of cases of severe acute respiratory syndrome in Hong Kong. N Engl J Med. 2003; 348:1977-85. https://doi.org/10.1056/NEJMoa030666 PMID: 12671062

29. Wang CJ, Ng CY, Brook RH. Response to COVID-19 in taiwan: big data analytics, new technology, and proactive testing. JAMA. 2020; 323:1341-42. https://doi.org/10.1001/jama.2020.3151 PMID:32125371

30. Leung GM, Lim WW, Ho LM, Lam TH, Ghani AC, Donnelly CA, Fraser C, Riley S, Ferguson NM, Anderson RM, Hedley AJ. Seroprevalence of IgG antibodies to SARS-coronavirus in asymptomatic or subclinical population groups. Epidemiol Infect. 2006; 134:211-21. https://doi.org/10.1017/S0950268805004826 PMID:16490123 


\section{SUPPLEMENTARY MATERIALS}

\section{Supplementary Figures}

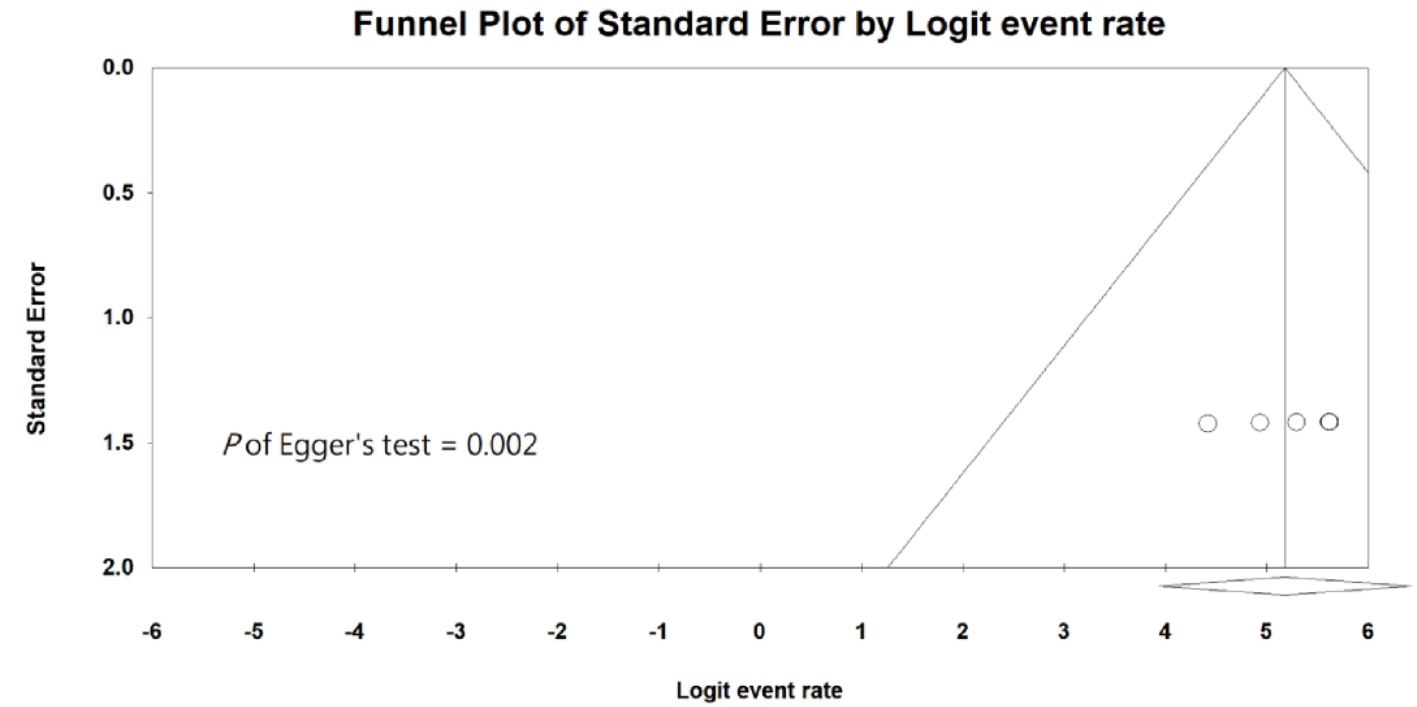

Supplementary Figure 1. Funnel plot for assessment of publication bias on lung infiltration from COVID-19 studies.

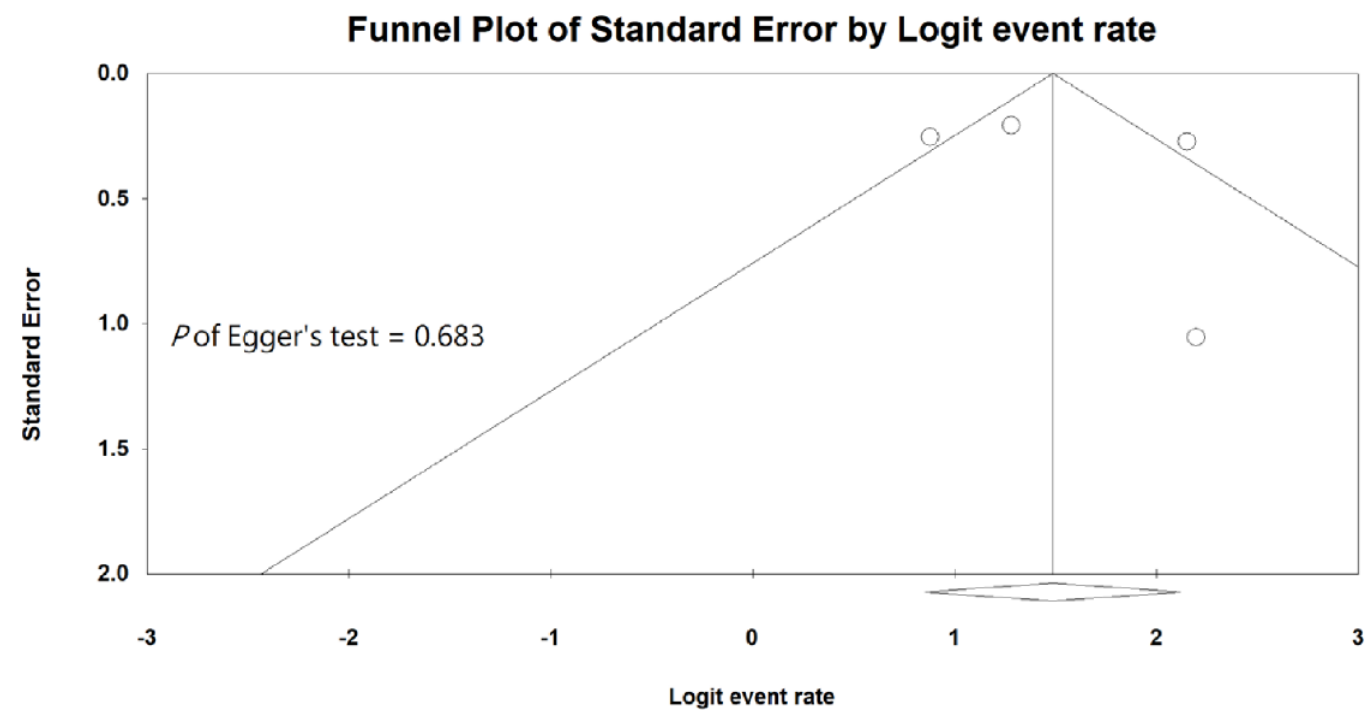

Supplementary Figure 2. Funnel plot for assessment of publication bias on lung infiltration from SARS studies. 


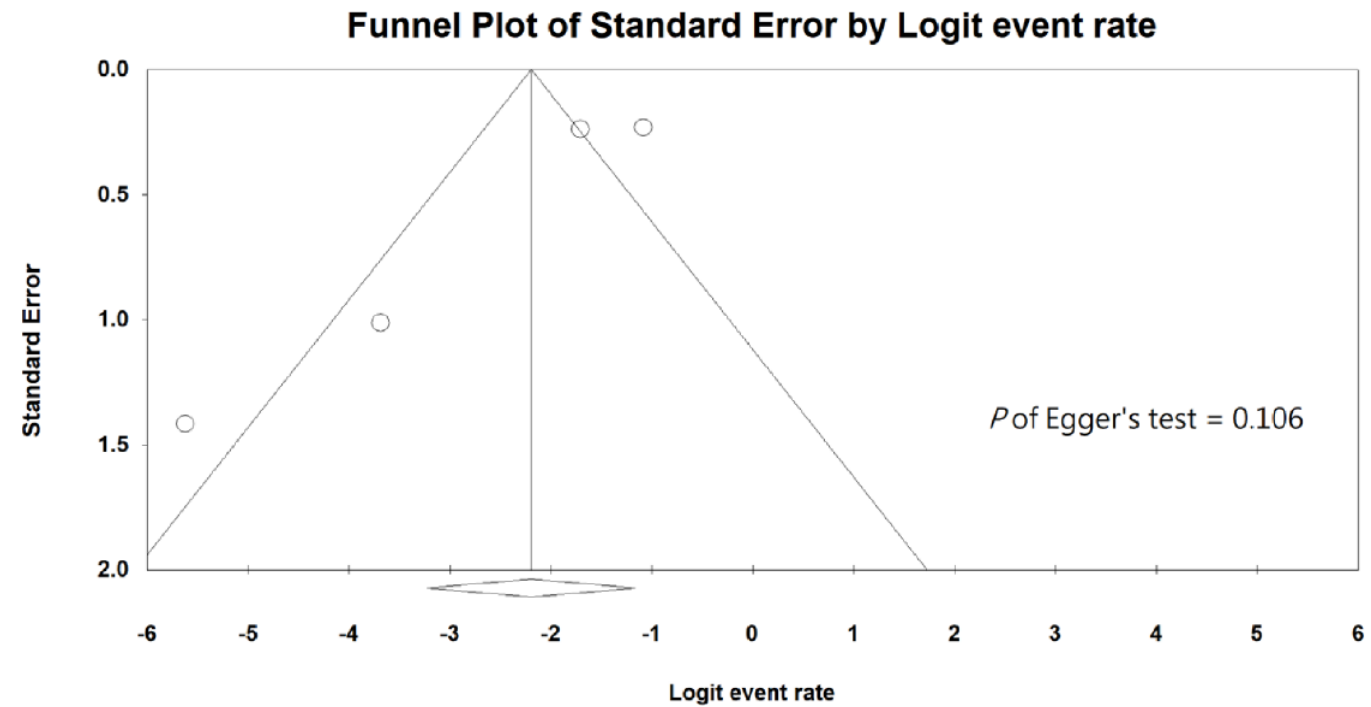

Supplementary Figure 3. Funnel plot for assessment of publication bias on unilateral pneumonia from COVID-19 studies.

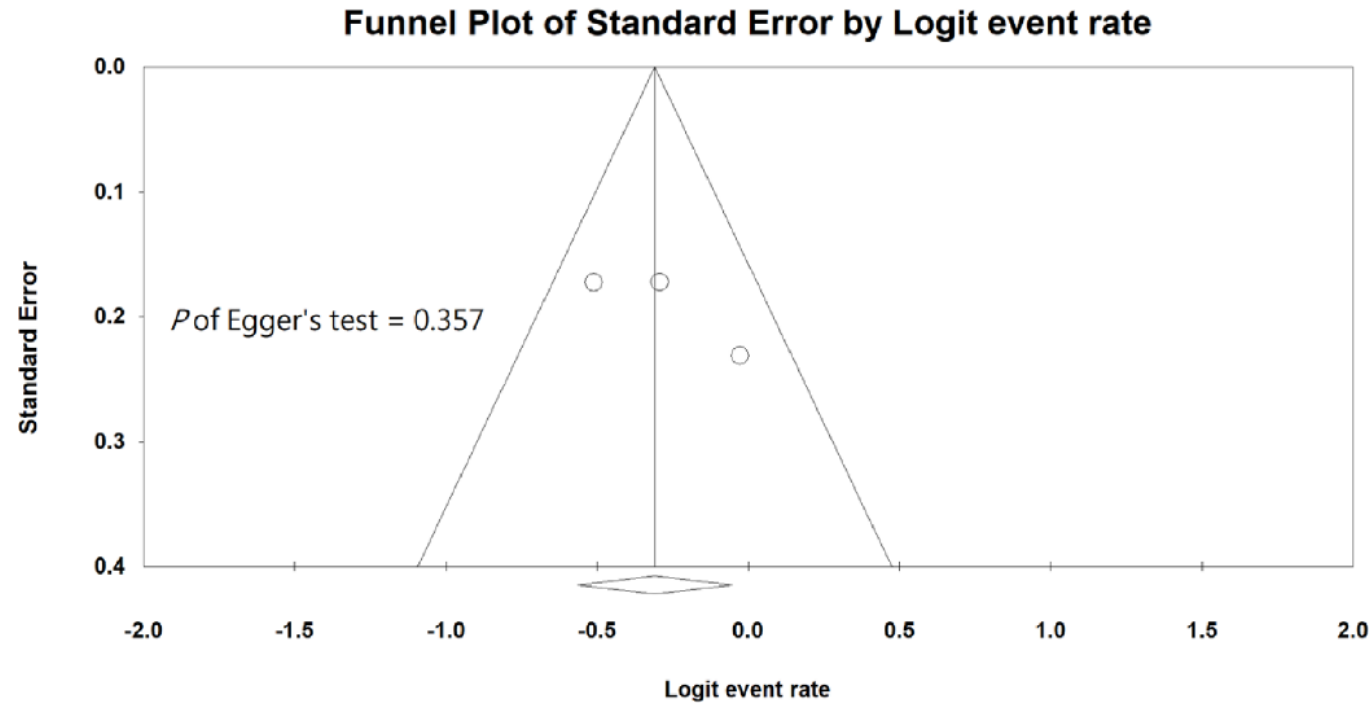

Supplementary Figure 4. Funnel plot for assessment of publication bias on unilateral pneumonia from SARS studies. 


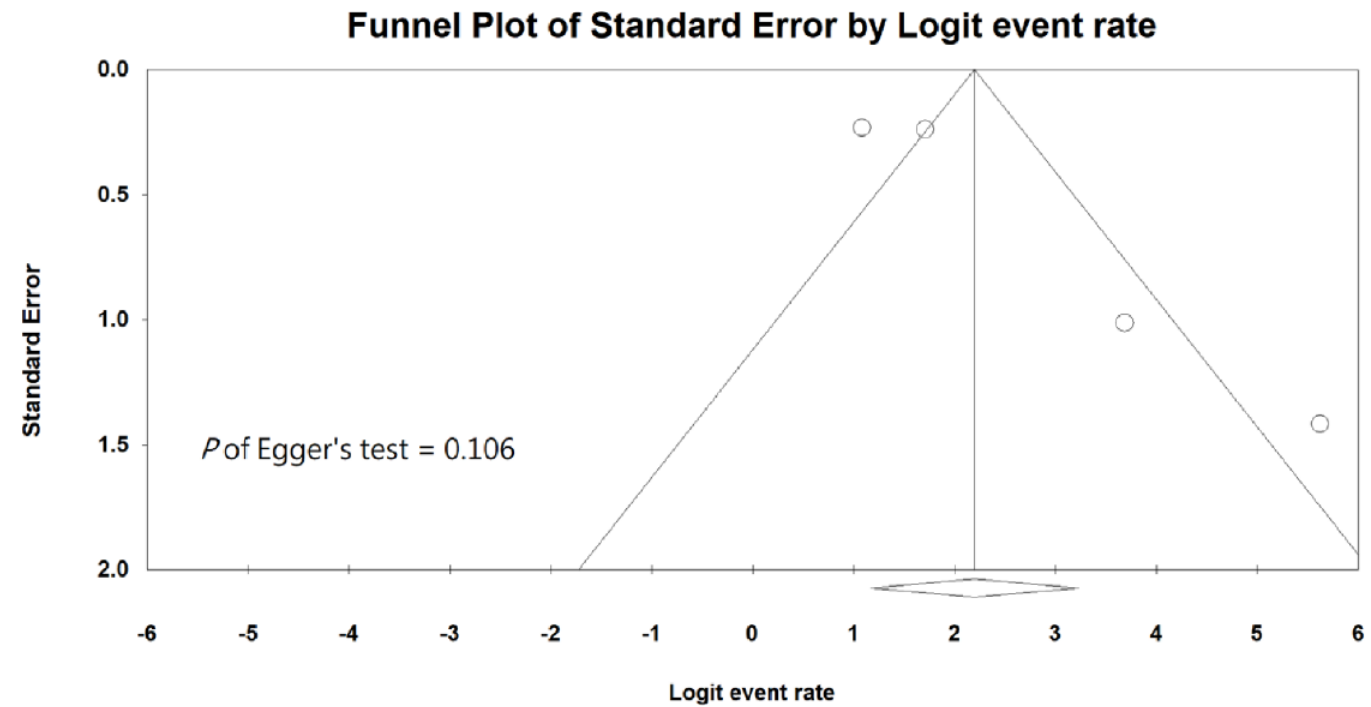

Supplementary Figure 5. Funnel plot for assessment of publication bias on bilateral pneumonia from COVID-19 studies.

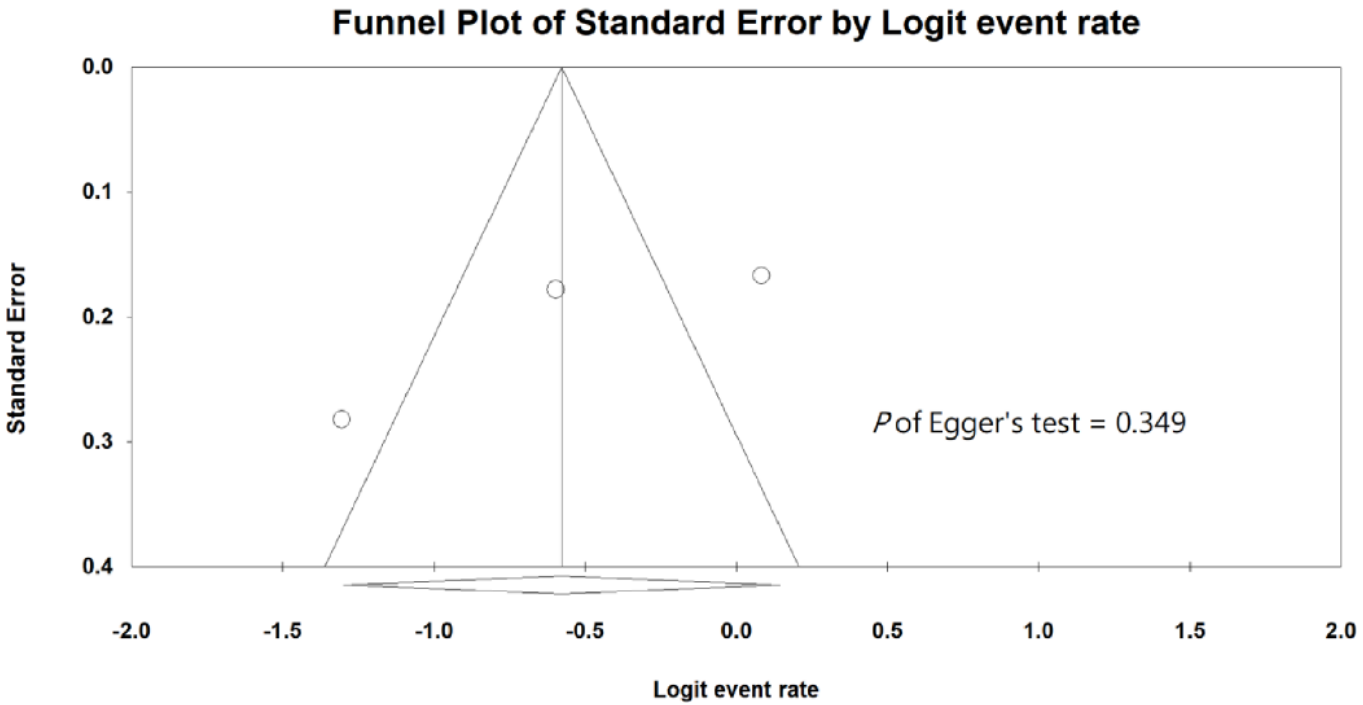

Supplementary Figure 6. Funnel plot for assessment of publication bias on bilateral pneumonia from SARS studies. 


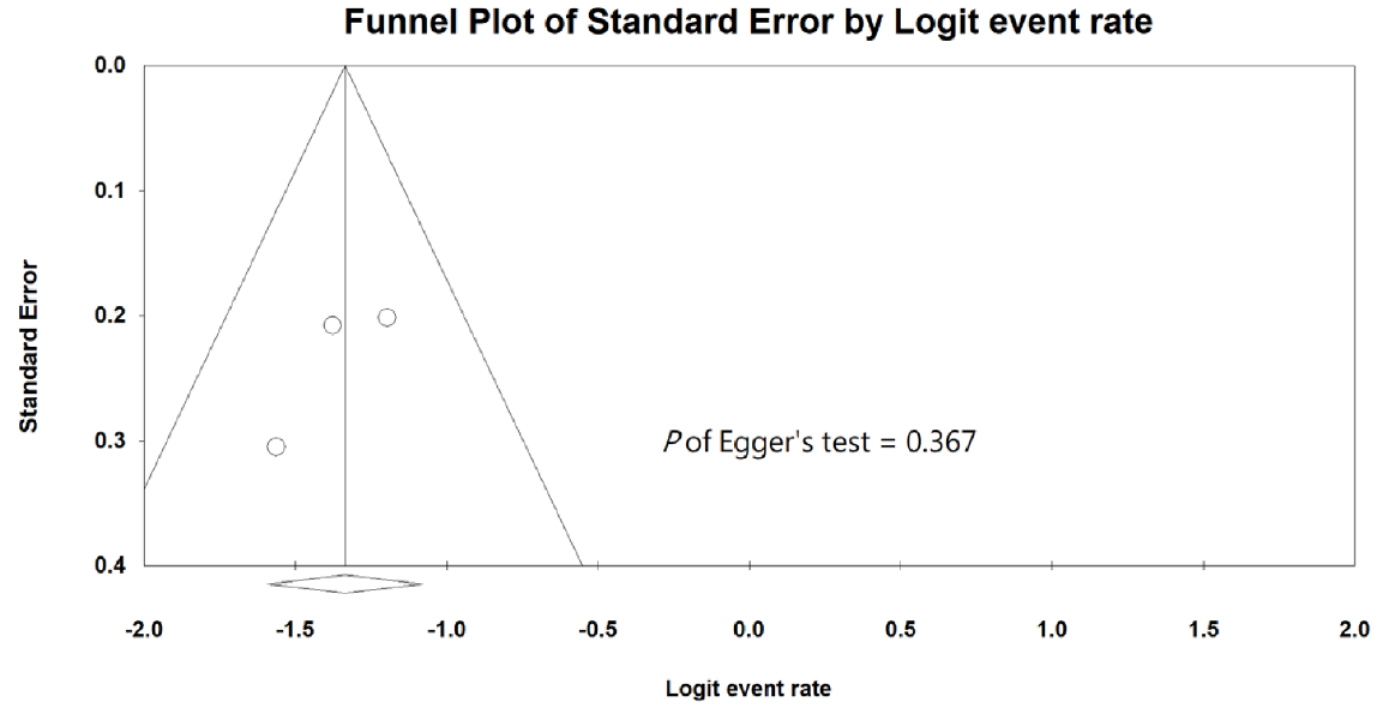

Supplementary Figure 7. Funnel plot for assessment of publication bias on ICU admission from SARS studies.

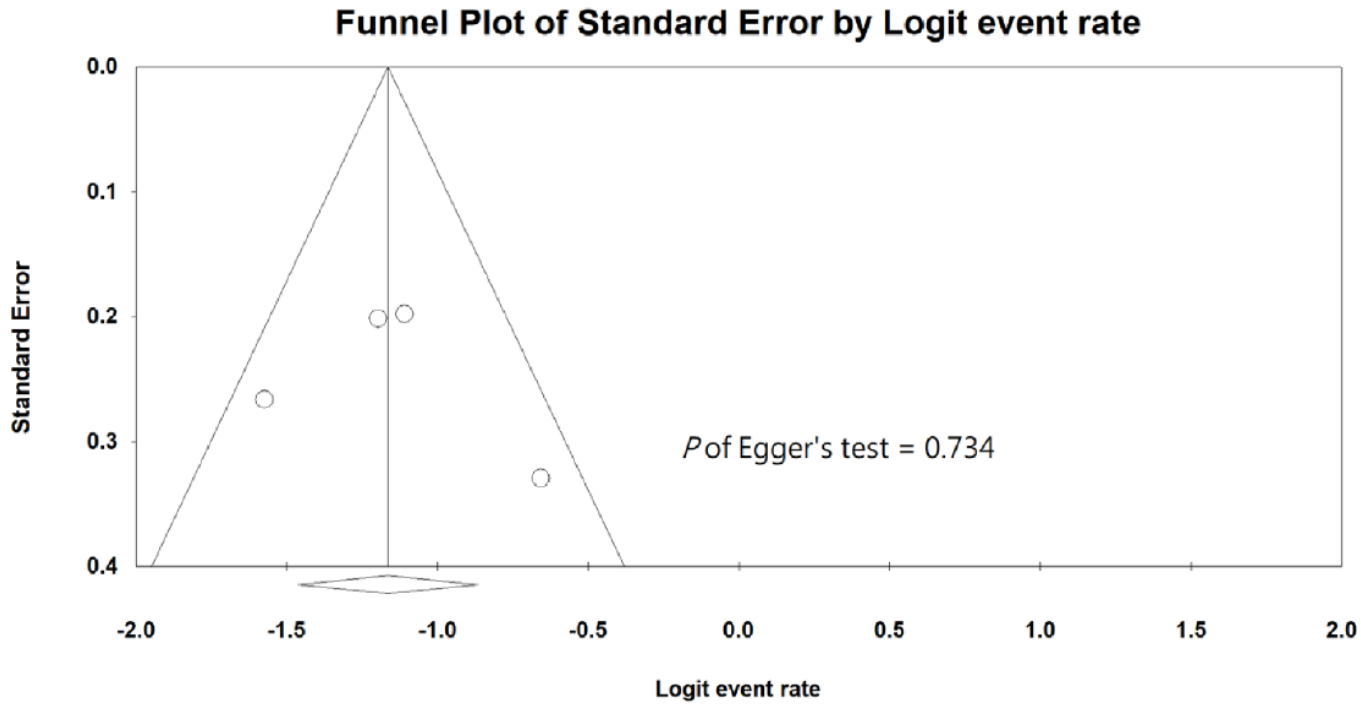

Supplementary Figure 8. Funnel plot for assessment of publication bias on ventilation from COVID-19 studies. 


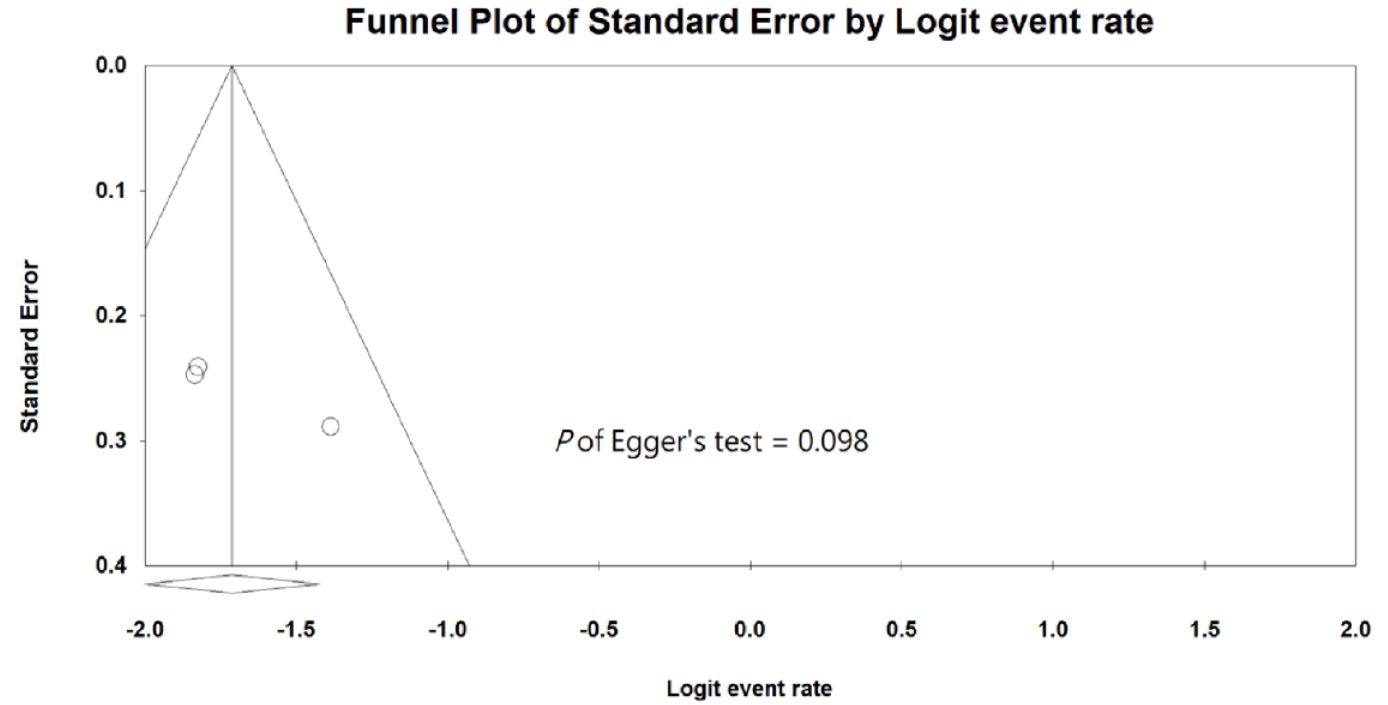

Supplementary Figure 9. Funnel plot for assessment of publication bias on ventilation from SARS studies.

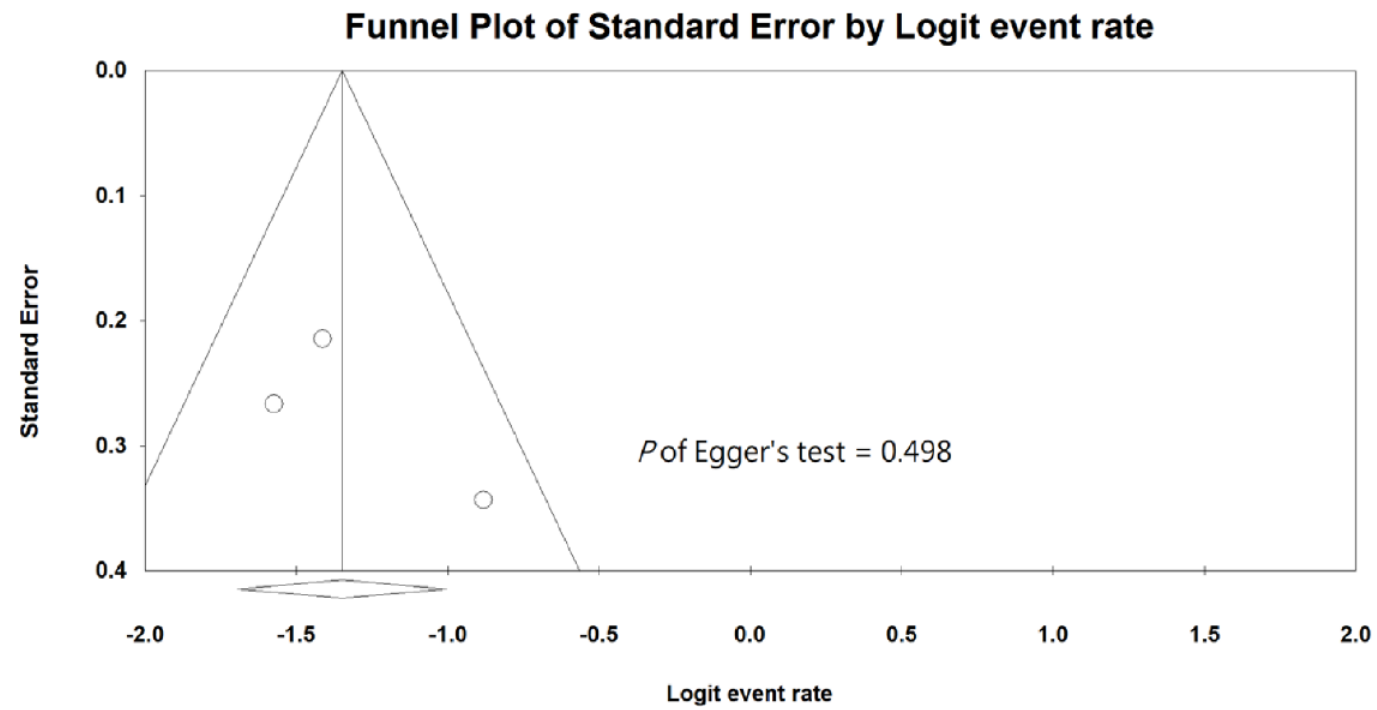

Supplementary Figure 10. Funnel plot for assessment of publication bias on ARDS from COVID-19 studies. 


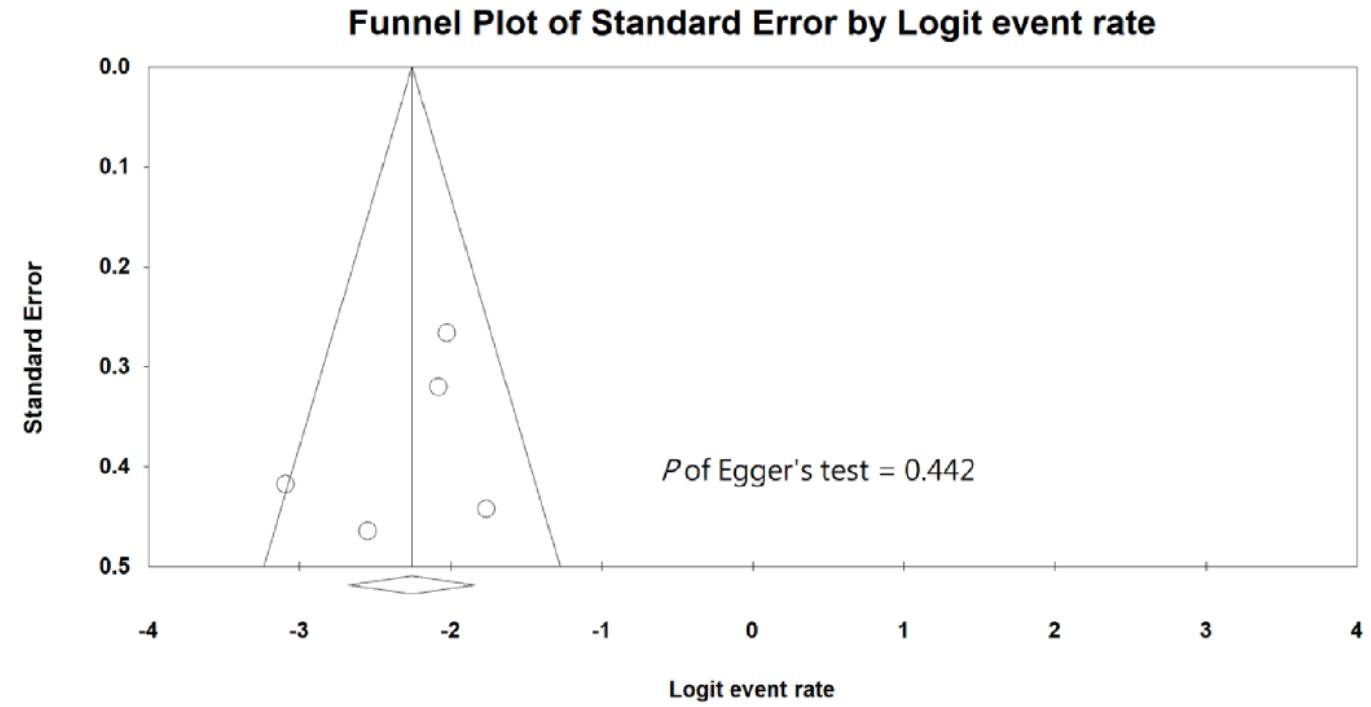

Supplementary Figure 11. Funnel plot for assessment of publication bias on death from COVID-19 studies.

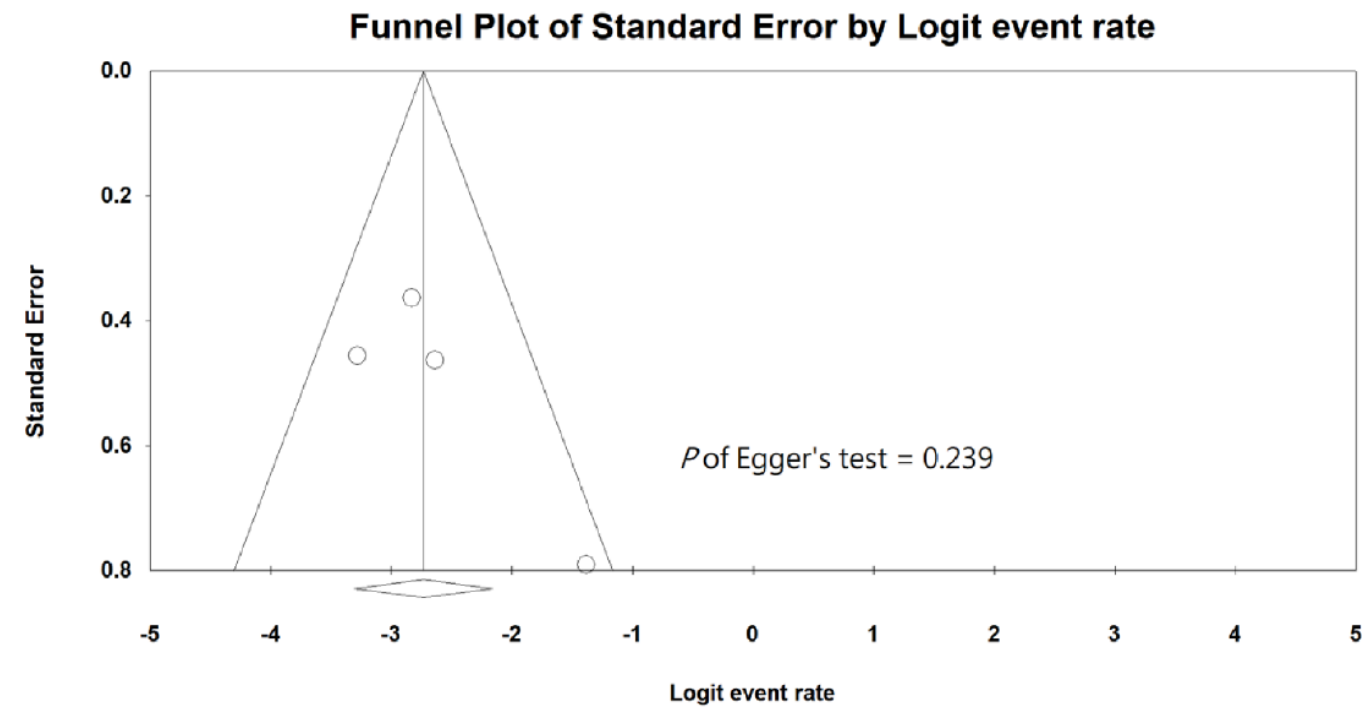

Supplementary Figure 12. Funnel plot for assessment of publication bias on ARDS from SARS studies. 


\section{Supplementary Table}

Supplementary Table 1. NHLBI and Research Triangle Institute International Scale Quality Assessment of included Studies.

\begin{tabular}{|c|c|c|c|c|c|c|c|c|c|}
\hline Criteria & 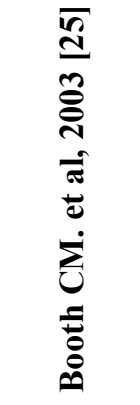 & 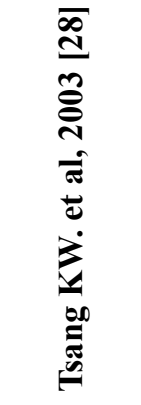 & 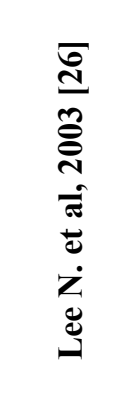 & 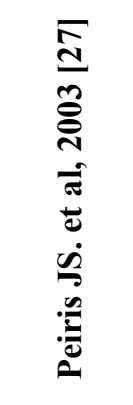 & 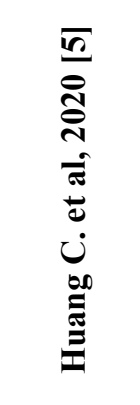 & 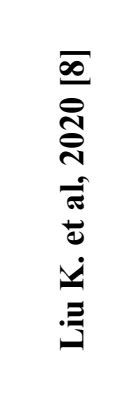 & 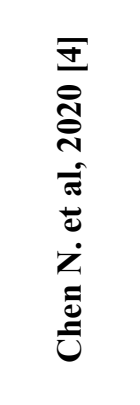 & 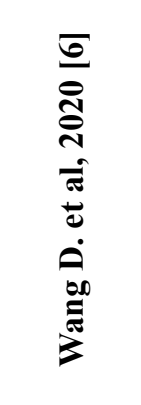 & 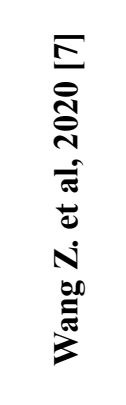 \\
\hline $\begin{array}{l}\text { Was the research question or } \\
\text { objective in this paper clearly } \\
\text { stated? }\end{array}$ & $\mathrm{Y} / \mathrm{Y}$ & $\mathrm{Y} / \mathrm{Y}$ & $\mathrm{Y} / \mathrm{Y}$ & $\mathrm{Y} / \mathrm{Y}$ & $\mathrm{Y} / \mathrm{Y}$ & $\mathrm{Y} / \mathrm{Y}$ & $\mathrm{Y} / \mathrm{Y}$ & $\mathrm{Y} / \mathrm{Y}$ & $\mathrm{Y} / \mathrm{Y}$ \\
\hline $\begin{array}{l}\text { Was the study population } \\
\text { clearly specified and defined? }\end{array}$ & $\mathrm{Y} / \mathrm{Y}$ & $\mathrm{Y} / \mathrm{Y}$ & $\mathrm{Y} / \mathrm{Y}$ & $\mathrm{Y} / \mathrm{Y}$ & $\mathrm{Y} / \mathrm{Y}$ & $\mathrm{Y} / \mathrm{Y}$ & $\mathrm{Y} / \mathrm{Y}$ & $\mathrm{Y} / \mathrm{Y}$ & $\mathrm{Y} / \mathrm{Y}$ \\
\hline $\begin{array}{l}\text { Was the participation rate of } \\
\text { eligible persons at least } 50 \% \text { ? }\end{array}$ & $\mathrm{Y} / \mathrm{Y}$ & $\mathrm{Y} / \mathrm{Y}$ & $\mathrm{Y} / \mathrm{Y}$ & $\mathrm{Y} / \mathrm{Y}$ & $\mathrm{Y} / \mathrm{Y}$ & $\mathrm{Y} / \mathrm{Y}$ & $\mathrm{Y} / \mathrm{Y}$ & $\mathrm{Y} / \mathrm{Y}$ & $\mathrm{Y} / \mathrm{Y}$ \\
\hline $\begin{array}{l}\text { Were all the subjects selected or } \\
\text { recruited from the same or } \\
\text { similar populations (including } \\
\text { the same time period)? Were } \\
\text { inclusion and exclusion criteria } \\
\text { for being in the study } \\
\text { prespecified and applied } \\
\text { uniformly to all participants? }\end{array}$ & $\mathrm{Y} / \mathrm{Y}$ & $\mathrm{Y} / \mathrm{Y}$ & $\mathrm{Y} / \mathrm{Y}$ & $\mathrm{Y} / \mathrm{Y}$ & $\mathrm{Y} / \mathrm{Y}$ & $\mathrm{Y} / \mathrm{Y}$ & $\mathrm{Y} / \mathrm{Y}$ & $\mathrm{Y} / \mathrm{Y}$ & $\mathrm{Y} / \mathrm{Y}$ \\
\hline $\begin{array}{l}\text { Was a sample size justification, } \\
\text { power description, or variance } \\
\text { and effect estimates provided? }\end{array}$ & NA/NA & NA/NA & NA/NA & NA/NA & NA/NA & NA/NA & NA/NA & NA/NA & NA/NA \\
\hline $\begin{array}{l}\text { For the analyses in this paper, } \\
\text { were the exposure(s) of interest } \\
\text { measured prior to the } \\
\text { outcome(s) being measured? }\end{array}$ & NA/NA & NA/NA & NA/NA & NA/NA & NA/NA & NA/NA & NA/NA & NA/NA & NA/NA \\
\hline $\begin{array}{l}\text { Was the timeframe sufficient so } \\
\text { that one could reasonably } \\
\text { expect to see an association } \\
\text { between exposure and outcome } \\
\text { if it existed? }\end{array}$ & NA/NA & NA/NA & NA/NA & NA/NA & NA/NA & NA/NA & NA/NA & NA/NA & NA/NA \\
\hline $\begin{array}{l}\text { For exposures that can vary in } \\
\text { amount or level, did the study } \\
\text { examine different levels of the } \\
\text { exposure as related to the } \\
\text { outcome (e.g., categories of } \\
\text { exposure, or exposure } \\
\text { measured as continuous } \\
\text { variable)? }\end{array}$ & NA/NA & NA/NA & NA/NA & NA/NA & NA/NA & NA/NA & NA/NA & NA/NA & NA/NA \\
\hline $\begin{array}{l}\text { Were the exposure measures } \\
\text { (independent variables) clearly } \\
\text { defined, valid, reliable, and } \\
\text { implemented consistently }\end{array}$ & NA/NA & NA/NA & NA/NA & NA/NA & NA/NA & NA/NA & $\mathrm{NA} / \mathrm{NA}$ & NA/NA & NA/NA \\
\hline
\end{tabular}


across all study participants?

Was the exposure(s) assessed more than once over time?

Were the outcome measures (dependent variables) clearly defined, valid, reliable, and implemented consistently across all study participants?

Were the outcome assessors blinded to the exposure status of participants?

Was loss to follow-up after baseline $20 \%$ or less?

$\begin{array}{ccccccccc}\text { NA/NA } & \text { NA/NA } & \text { NA/NA } & \text { NA/NA } & \text { NA/NA } & \text { NA/NA } & \text { NA/NA } & \text { NA/NA } & \text { NA/NA } \\ \text { Y/Y } & \text { Y/Y } & \text { Y/Y } & \text { Y/Y } & \text { Y/Y } & \text { Y/Y } & \text { Y/Y } & \text { Y/Y } & \text { Y/Y }\end{array}$

NA/NA NA/NA NA/NA NA/NA NA/NA NA/NA NA/NA NA/NA NA/NA

$\begin{array}{lllllllll}\mathrm{Y} / \mathrm{Y} & \mathrm{Y} / \mathrm{Y} & \mathrm{Y} / \mathrm{Y} & \mathrm{Y} / \mathrm{Y} & \mathrm{Y} / \mathrm{Y} & \mathrm{Y} / \mathrm{Y} & \mathrm{Y} / \mathrm{Y} & \mathrm{Y} / \mathrm{Y} & \mathrm{Y} / \mathrm{Y}\end{array}$

Were key potential confounding NA/NA NA/NA NA/NA NA/NA NA/NA NA/NA NA/NA NA/NA NA/NA variables measured and adjusted statistically for their impact on the relationship between exposure(s) and outcome(s)?

Overall quality rating Good Good Good Good Good Goo Good Good Good

Source of the quality assessment tool: https://www.nhlbi.nih.gov/health-topics/study-quality-assessment-tools 


\section{Supplementary Material}

\section{Supplementary Material 1. The exact string of keywords used to do the search in each database.}

Embase:

('severe acute respiratory distress syndrome' OR 'sars'/exp OR '2019-ncov' OR 'covid 19'/exp) AND ('case report'/de OR 'clinical article'/de) AND 'human'/de AND 'article'/it

Medline+Journals@Ovid

((severe acute respiratory syndrome or SARS or SARS-CoV-2 or COVID-19) and coronavirus and cases).mp. [mp=title, abstract, original title, name of substance word, subject heading word, floating sub-heading word, keyword heading word, organism supplementary concept word, protocol supplementary concept word, rare disease supplementary concept word, unique identifier, synonyms]

Pubmed:

((severe acute respiratory syndrome) or (SARS) or (SARS-CoV-2) or (COVID-19)) and (coronavirus) and (patient)

Filters: Journal Article, Human, English

Search date: $2020 / 05 / 04$ 